Marquette University

e-Publications@Marquette

Psychology Faculty Research and Publications

Psychology, Department of

6-1-1997

Caregiver and Clinician Assessment of Behavioral Disturbances: The California Dementia Behavior Questionnaire

Jeff Victoroff

University of Southern California

Kristy A. Nielson

Marquette University, kristy.nielson@marquette.edu

Dan Mungas

University of California - Davis

Published version. International Psychogeriatrics, Vol. 9, No. 2 (June 1997): 155-174. DOI. (C) 1997 Cambridge University Press. Used with permission.

Kristy Nielson was affiliated with the University of California - Irvine at the time of publication. 


\title{
Caregiver and Clinician Assessment of Behavioral Disturbances: The California Dementia Behavior Questionnaire
}

\author{
Jeff Victoroff, Kristy Nielson, and Dan Mungas
}

\begin{abstract}
As part of a multicenter project to study noncognitive behavioral disturbances in dementia, the authors developed a comprehensive caregiver-rated questionnaire for these behaviors. The authors determined the reliability of caregiver ratings and compared caregiver ratings with clinician ratings using standard instruments. Caregivers showed good test/retest reliability for ratings of all types of patient behavioral disturbance. Caregiver interrater reliability was highest for depression and lowest for psychosis. The correlation between caregiver reports and professional assessments was highest for agitation, intermediate for psychosis, and lowest for depression. The match between caregiver and clinician assessments of patient behaviors appears to vary significantly by the type of behavior assessed.
\end{abstract}

Noncognitive behavioral disturbances have recently come to be recognized as an important component of Alzheimer's disease (AD) and related dementias. Major depressive symptoms have been reported in $6 \%$ to $86 \%$ of demented patients, delusions have been reported in $16 \%$ to $57 \%$, hallucinations in $17 \%$ to $32 \%$, and some form of agitation or aggression has been reported in $26 \%$ to

From the Department of Neurology, University of Southern California School of Medicine, Los Angeles, California (J. Victoroff, MD); the Institute for Brain Aging and Dementia, University of California Irvine, Irvine, California (K. Nielson, PhD); Department of Neurology, University of California Davis School of Medicine, Davis, California, USA (D. Mungas, PhD).

Offprints. Requests for offprints should be directed to Jeff Victoroff, MD, Department of Neurology, University of Southern California School of Medicine, Rancho Los Amigos Medical Center, 7601 E. Imperial Highway, Downey, CA 90242, USA.
$83 \%$ of cases (Burns et al., 1990; Cummings \& Victoroff, 1990; Cummings et al., 1995; Gilley et al., 1991; Kumar et al., 1988; Merriam et al., 1988; Sattel et al., 1993; Swearer et al., 1988; Teri et al., 1988). Caregivers are often the principal observers of these behaviors; may experience increased burden, stress, and depression because of them; and may make placement decisions based primarily on the basis of the occurrence of these behaviors (Chenoweth \& Spencer, 1986; Cohen et al., 1993).

Several scales and instruments have been developed to assess behavioral disturbances among the demented elderly (Asada et al., 1994; de Jonghe et al., 1995; Patterson \& Bolger, 1994; Weiner et al., 1996). In a recent review (Weiner et al., 1996), the caregiver is noted to be an informant for 13 of $16(81 \%)$ of such instruments. However, little is known about the reliability or validity of care- 
giver observations of patient behaviors, or how caregiver assessments compare with clinician assessments. As CohenMansfield (1995) has observed, caregiver ratings of behavioral disturbance may be easier to obtain and have significant clinical relevance especially regarding caregiver burden, but they may be more subjective, biased by the caregiver's relationship to the patient and the caregiver's burden. Conversely, clinician ratings typically have the disadvantage of representing a shorter period of observation and, especially in the outpatient setting, may actually be substantially based on caregiver information. Further, validation of caregiver ratings has typically not been adequately explored because of the lack of external measures.

A few previous studies have specifically addressed the concordance between caregiver and clinician ratings of noncognitive behavioral disturbances in dementia. Teri and Wagner (1991) compared the results when clinicians completed the Hamilton Depression Inventory based on patient reports, caregiver reports, or the clinician's overall judgment. In that study, clinicians and caregivers had similar ratings of depressed patients, but clinicians reported more depression than caregivers among nondepressed patients. The results must be interpreted with caution because the caregivers' ratings were actually completed by the clinicians, making it possible that clinician bias might have influenced the way clinicians transferred the caregiver observations to the reporting instrument. Seltzer and Buswell (1994) compared clinician ratings of patient behavior with caregiver ratings on a questionnaire addressing the same behaviors. They found that caregivers re- ported a greater prevalence of behavioral problems than clinicians in 8 of 12 categories including depression, delusions, and hallucinations. The authors concluded that the clinicians' ratings were superior to the caregivers' because clinician ratings exhibited a higher correlation with measures of cognition and everyday activities. However, in that study the clinicians used a nonstandard rating method. Neither Teri and Wagner nor Seltzer and Buswell reported the reliability of caregiver ratings. Lukovits and McDaniel (1992) compared family member's and nurses' ratings on a 13item questionnaire of behavioral disturbance in Alzheimer's disease. Family members and nurses often disagreed, with family members more frequently reporting decreased interest, agitation, and depression. In this study, again, there was no validation or comparison of the rating method with standard instruments, and no measure of rater reliability.

Thus, although caregiver reports may often be a principal source of information about patient behaviors in dementia, the relationship between caregiver observations and professional ratings remains unclear. This may be a critical issue for documenting these disturbances, determining their clinical significance, and studying the response to treatments.

As part of a multicenter project to assess noncognitive behaviors in Alzheimer's disease and related dementias, we developed a new instrument to assess caregiver observations of patient behavioral disturbances. We examined the reliability of caregiver ratings, the internal consistency of subscales of the instrument addressing specific aspects of behavior, and the correlation between 
caregiver ratings and clinician ratings of the same aspects of behavior.

\section{METHODS}

Representatives from each of nine university-affiliated Alzheimer's Disease Diagnostic and Treatment Centers supported by the California Department of Health Services (ADDTCs) met to develop a list of noncognitive behavioral symptoms considered important in the assessment of dementia. The conference included two neuropsychologists, one clinical psychologist, two neurologists, one neuropsychiatrist, one geriatrician, and two biostatisticians, all engaged in clinical and research programs in dementia. A list of 45 behavioral issues was selected by consensus, based on literature review and the clinical experience of the conference attendees.

Two pilot projects were carried out independently, one at the University of Southern California (USC) and the other at the University of California Davis (UCD). In each pilot project, a caregivercompleted questionnaire was prepared, rating the target behaviors. The USC $\mathrm{pi}$ lot questionnaire consisted of 32 items assessing mood, delusions, hallucinations, and agitation. The items in the USC instrument were adapted from established instruments for behavioral assessment including the Brief Psychiatric Rating Scale (BPRS) (Overall \& Gorham, 1962), the Behavioral Pathology in Alzheimer's Disease Rating Scale (BEHAVEAD) (Reisberg et al., 1987), the Columbia University Scale for Psychopathology in Alzheimer's Disease (CUSPAD) (Devanand et al., 1992), the Hamilton Depression Inventory (HDI) (Hamilton,
1960), the Cornell Scale for Depression in Dementia (CSD) (Alexopoulos et al., 1988), and the Cohen-Mansfield Agitation Inventory (CMAI) (Cohen-Mansfield et al., 1989). The UCD pilot questionnaire consisted of 58 items designed to match the consensus of items that had been agreed on in the consensus conference. In a revision, a separate 19item section was added, focusing on changes in mood and emotion noted during the last month.

Based on caregiver feedback and examination of data from the pilot instruments, investigators from both sites collaborated to produce a final draft consisting of a three-part instrument: (a) a 62 -item questionnaire rating behaviors by frequency on a four-step Likert-type scale of degree of frequency for each behavior, from "never" to "constantly"; (b) a 19-item section rating mood and emotion on a three-step scale of severity; and (c) a 6-item section for caregiver ratings of their own stress and depressive symptoms including 3 items derived from the Zarit Caregiver Burden Inventory (Zarit et al., 1980) and 3 items from the Zung Self-rating Depression Scale (Zung, 1965). This instrument is referred to as the California Dementia Behavior Questionnaire (CDBQ) (see Appendix).

The CDBQ was distributed to primary caregivers of patients with cognitive complaints diagnosed at three sites during consecutive outpatient clinic visits. Caregivers were instructed to complete the $C D B Q$ by reading the introductory instructions on the form (see Appendix) and by a brief verbal explanation matching these instructions. The questionnaires were regarded as complete if answers to all items were recorded. Three hundred forty-three instruments were 
distributed, of which 258 were returned complete. Of these 258,167 subjects were seen at UCD, 77 at USC, and 14 at the University of California at Irvine (UCI). Demographic characteristics of the subject population are provided in Table 1. There was no difference in patient age by site, but a higher proportion of patients at UCD and USC were women, whereas a higher proportion of patients at $\mathrm{UCI}$ were men (UCD $=67.7 \%$ women, $\mathrm{USC}=74.0 \%$ women, $\mathrm{UCI}=35.7 \%$ women; $\chi^{2}=7.97, d f=2, p=.02$ ).

TABLE 1. Demographics of 258 Subjects by Site

\begin{tabular}{|c|c|c|c|}
\hline & $n$ & Age $^{a}$ & Gender \\
\hline UCD & 167 & $75.9(8.8)$ & $54 \mathrm{M} ; 113 \mathrm{~F}$ \\
\hline USC & 77 & $75.5(8.8)$ & $20 \mathrm{M} ; 57 \mathrm{~F}$ \\
\hline UCI & 14 & $72.9(10.1)$ & $9 \mathrm{M} ; 5 \mathrm{~F}$ \\
\hline Totals & 258 & $75.6(8.9)$ & $83 \mathrm{M} ; 175 \mathrm{~F}$ \\
\hline
\end{tabular}

TABLE 2. Clinical Diagnoses of 258

Subjects

\begin{tabular}{lr}
\hline Clinical Diagnosis & $n$ \\
\hline Demented & 160 \\
Probable Alzheimer's disease & 30 \\
Possible Alzheimer's disease & 6 \\
Probable ischemic vascular dementia & 2 \\
Possible ischemic vascular dementia & 14 \\
Mixed Alzheimer's and vascular & 1 \\
Parkinson's disease & 8 \\
Lewy body disease & 5 \\
Picks/frontal lobe dementia & 2 \\
Progressive supranuclear palsy & 17 \\
Demented, etiology undetermined & \\
Nondemented & 1 \\
Amnestic syndrome & 1 \\
Age-associated memory impairment & 8 \\
Other cognitive impairment & 1 \\
No cognitive impairment & 2 \\
Syndrome undetermined & \\
\hline
\end{tabular}

Probable and possible AD were diagnosed according to National Institute for Neurologic and Communicative Disorders and Stroke criteria (McKhann et al., 1984). Probable and possible ischemic vascular dementia (IVD) were diagnosed according to the ADDTC criteria (Chui et al., 1992). Other clinical diagnoses were made according to a clinician-team consensus. Clinical diagnoses of the study population are listed in Table 2.

Interrater reliability was determined as follows: 73 patients at UCD were identified, for which two caregivers independently completed the CDBQ on the same visit. In this group of patients, the mean age was 77.9 years; $69 \%$ were female. Dementia diagnoses in this group included $71 \%$ probable or possible $A D$, $3 \%$ probable or possible IVD, $7 \%$ mixed dementia, 7\% Lewy body dementia (LBD), and $12 \%$ other dementias. Testretest reliability was determined as follows: in 37 cases at UCD and 6 at USC, the same caregiver completed the CDBQ at the time of the initial evaluation and 1 to 2 weeks later. Mean age of patients in this group was 77.7 years; $79 \%$ were female. Diagnoses included $80 \%$ probable or possible $\mathrm{AD}, 5 \%$ probable or possible IVD, 5\% mixed dementia, 5\% LBD, and $5 \%$ other dementias. Correlations between caregiver ratings and clinician ratings were determined as follows: in 51 consecutive cases at USC and 15 cases at UCI (total of 66 cases), a clinician interviewed the caregivers and examined the patients during the same clinic visit shortly after caregivers completed the CDBQ. In so far as possible, the clinician's objective observations were used to complete items intended to be based on the patient examination, and the information thus obtained was used to complete the matching items on differ- 
ent instruments. However, in the case of infrequently occurring behaviors (e.g., episodes of physical aggression), the caregiver's report was considered in the clinician's assessment. At USC, the clinician was board certified in neurology and psychiatry. At $\mathrm{UCl}$, the clinician was a neuropsychologist. Mean age of patients in this group of 66 patients was 73.7 years; $48.9 \%$ were female. Diagnoses included $85 \%$ probable or possible $\mathrm{AD}$, $2 \%$ probable or possible IVD, $7 \%$ mixed dementia, $4 \% \mathrm{LBD}$, and $2 \%$ other. The mean Mini-Mental State Examination score of this group was 12.5 (range $=0$ to $27 ; S D=7.1$ ). Clinicians rated patient behaviors on a battery of standard instruments including the BPRS, the CUSPAD, the HDI, the CSD, and the CMAI. Note that caregiver and clinician ratings were carried out on the same clinic visit, and both assessed behavior for the same time interval (i.e., the previous month). The exception to this was the cliniciancompleted HDI, which did not exactly match the period assessed by the caregivers because it specifies behavior in the previous week. The 51 cases at USC were also evaluated using the BEHAVEAD. Items 13 to 18 of the BEHAVE-AD assess aspects of agitation, so these items were used as an agitation subscale. Items 1 to 16 of the CUSPAD assess aspects of psychosis, so these items were used as a psychosis subscale.

\section{Data Analysis}

The data from the CDBQs were approached in two ways. First, a total score for behavioral disturbance in the previous month was derived for the 62 items rated for frequency $(0=$ never, $1=$ rarely, $2=$ weekly, $3=$ daily, and $4=$ constantly). A total score was also derived for the 19 items rating mood disturbance in the previous month by severity $(0=$ not present, $1=$ mild, $2=$ moderate, and $3=$ severe). Second, three subscales of the $C D B Q$ were defined that matched, item by item, with standard clinician-rated

TABLE 3. Item Content of Depression Subscale

\begin{tabular}{cc}
\hline Item \# & \multicolumn{1}{c}{ Content } \\
\hline I. & Behaviors rated by frequency \\
6 & Talks about feeling sad or depressed \\
7 & Is tearful \\
8 & Talks about being a failure, \\
inadequate or worthless \\
9 & Talks about things she/he has done \\
& wrong \\
10 & Complains of problems with \\
& thinking or concentration \\
11 & Says life is not worth living \\
12 & Talks about suicide \\
13 & Worries too much about things \\
14 & Has episodes of extreme anxiety or \\
& panic \\
27 & Complains of trouble sleeping \\
28 & Has difficulty sleeping at night \\
32 & Has poor appetite \\
34 & Has lost weight \\
42 & Has unreal belief that she/he has a \\
\multicolumn{3}{c}{ serious illness or physical problem } \\
43 & Has unreal belief that her/his body \\
\multicolumn{3}{|l}{ is not working properly } \\
II. Changes in mood rated by severity \\
1 & Appears sad or depressed \\
2 & Does not seem to enjoy anything \\
3 & Has low energy, becomes tired easily \\
4 & Is nervous, anxious, or tense \\
8 & Is agitated or distressed \\
10 & Has little or no interest in things \\
11 & Does not seem to care about \\
& anything \\
12 & Not interested in interacting with \\
13 & others \\
15 & Shows little emotional response \\
16 & Is restless or overactive \\
19 & Speaks or moves slowly \\
\hline & Thinks slowly \\
\hline
\end{tabular}


TABLE 4. Item Content of Psychosis Subscale

\begin{tabular}{|c|c|}
\hline Item \# & Content \\
\hline 39 & Is irrationally jealous \\
\hline 40 & Is very suspicious \\
\hline 41 & $\begin{array}{l}\text { Believes others are plotting against } \\
\text { or want to hurt her/him }\end{array}$ \\
\hline 42 & $\begin{array}{l}\text { Has unreal belief that she/he has a } \\
\text { serious illness or physical problem }\end{array}$ \\
\hline 43 & $\begin{array}{l}\text { Has unreal belief that her/his body } \\
\text { is not working properly }\end{array}$ \\
\hline 44 & $\begin{array}{l}\text { Has unreal belief that she/he has } \\
\text { exceptional powers, talents, or } \\
\text { abilities }\end{array}$ \\
\hline 45 & $\begin{array}{l}\text { Believes that people are stealing } \\
\text { things from her / him }\end{array}$ \\
\hline 46 & $\begin{array}{l}\text { Believes spouse or significant other } \\
\text { has been unfaithful }\end{array}$ \\
\hline 47 & Believes she/he will be abandoned \\
\hline 48 & $\begin{array}{l}\text { Believes that spouse or caregiver is } \\
\text { an imposter }\end{array}$ \\
\hline 49 & $\begin{array}{l}\text { Believes that place she/he is living } \\
\text { is not her/his home }\end{array}$ \\
\hline 50 & Believes TV shows are real \\
\hline 53 & $\begin{array}{l}\text { Sees people or objects that aren't } \\
\text { there }\end{array}$ \\
\hline 54 & Sees lights or colors that aren't there \\
\hline 55 & $\begin{array}{l}\text { Hears words or voices that aren't } \\
\text { there }\end{array}$ \\
\hline 56 & Hears sounds that aren't there \\
\hline 57 & $\begin{array}{l}\text { Feels sensations (like being touched) } \\
\text { when there's nothing there }\end{array}$ \\
\hline 58 & Smells odors that aren't there \\
\hline 59 & Tastes things that aren't there \\
\hline
\end{tabular}

instruments: (a) depression, based on items derived from the CSDD and the HDI (Table 3); (b) psychosis, based on items derived from the CUSPAD and the BEHAVE-AD (Table 4); and (c) agitation, based on items derived from the CMAI (Table 5). Some questions are part of more than one subscale because they may be regarded as symptoms of more than one behavioral problem (e.g., so-
TABLE 5. Item Content of Agitation Subscale

\begin{tabular}{|c|c|}
\hline Item \# & Content \\
\hline \multicolumn{2}{|c|}{ I. Behaviors rated by frequency } \\
\hline 17 & $\begin{array}{l}\text { Engages in inappropriate sexual } \\
\text { behavior }\end{array}$ \\
\hline 18 & $\begin{array}{l}\text { Displays other embarrassing or } \\
\text { inappropriate behavior }\end{array}$ \\
\hline 19 & Wanders \\
\hline 20 & Paces back and forth \\
\hline 21 & $\begin{array}{l}\text { Follows caregiver wherever she/he } \\
\text { goes }\end{array}$ \\
\hline 22 & Hides or hoards things \\
\hline 23 & Engages in purposeless activity \\
\hline 24 & $\begin{array}{l}\text { Repeats same behavior over and } \\
\text { over }\end{array}$ \\
\hline 25 & Repeats questions or stories \\
\hline 26 & Is fidgety, can't sit still \\
\hline 35 & $\begin{array}{l}\text { Is physically violent with other } \\
\text { people }\end{array}$ \\
\hline 36 & $\begin{array}{l}\text { Hits, kicks, or throws objects in } \\
\text { anger }\end{array}$ \\
\hline 37 & Has verbal outbursts of anger \\
\hline 38 & Uncooperative with caregiver \\
\hline \multicolumn{2}{|c|}{ II. Changes in mood rated by severity } \\
\hline 5 & Reacts angrily to minor frustrations \\
\hline 6 & Demands must be met immediately \\
\hline 7 & Is excitable or impulsive \\
\hline 8 & Is agitated or distressed \\
\hline 9 & $\begin{array}{l}\text { Mood or emotions change quickly } \\
\text { and dramatically }\end{array}$ \\
\hline 15 & Is restless or overactive \\
\hline
\end{tabular}

matoform delusions may be regarded as evidence of depression or psychosis).

CDBQs were included in the analyses of total scores if they were filled out completely. CDBQs were included in the analyses of subscale scores if all of the pertinent subscale items were completed. Coefficient $\alpha$ was calculated as a measure of internal consistency for each of the three subscales. Pearson correlation coefficients were determined for test- 
retest reliability, interrater reliability, and caregiver-clinician comparisons.

\section{RESULTS}

\section{Internal Consistency of CDBQ Subscales}

Based on 258 individual cases with completed questionnaires: coefficient $\alpha$ for the 27 items of the depression subscale $=$ 0.924 . Coefficient $\alpha$ for the 19 items of the psychosis subscale $=0.911$. Coefficient $\alpha$ for the 19 items of the agitation subscale $=0.917$.

\section{Reliability}

Test/retest reliability was examined for subscale scores. Because subscales were excluded from analysis if even a single item was incomplete, the number of cases analyzed for each subscale was lower than the total number of instruments collected. Test/retest correlations were high for all three subscales (see Table 6).

TABLE 6. Reliability of Caregiver

Behavioral Ratings

\begin{tabular}{lcc}
\hline & $n$ & Correlation \\
\hline Test/retest reliability & & \\
$\quad$ Subscale & & \\
$\quad$ Depression & 19 & .91 \\
$\quad$ Psychosis & 28 & .88 \\
$\quad$ Agitation & 26 & .90 \\
Interrater reliability & & \\
$\quad$ Subscale & & \\
$\quad$ Depression & 29 & .84 \\
$\quad$ Psychosis (total score) & 39 & .36 \\
$\quad$ Delusions & 30 & .20 \\
$\quad$ Hallucinations & 33 & .56 \\
$\quad$ Agitation & 33 & .53 \\
\hline
\end{tabular}

Interrater reliability was also examined for subscale scores, again with incomplete items reducing the total included in this analysis. Interrater correlation was high for the depression subscale (0.84), but lower for agitation and psychosis subscales (see Table 6). When the psychosis subscale was divided into items assessing delusions or hallucinations, we found a much higher interrater correlation for hallucinations $(0.56)$ than for delusions (0.20).

\section{CDBQ Scores}

Based on 258 cases with complete questionnaires, the mean total score on questions 1 to 62 was 112.36 (range $=62$ to $286 ; S D=34.64)$. The mean total score on mood questions 1 to 19 was 38.30 (range $=19$ to $76 ; S D=13.42$ ). The mean total score on the depression subscale was 51.31 (range $=28$ to $123 ; S D=16.51$ ). The mean total score on the psychosis subscale was 26.02 (range $=19$ to $91 ; S D=$ 10.33). The mean total score on the agitation subscale was 39.48 (range $=20$ to 85 ; $S D=15.14$ ). An analysis of variance model was used to determine if dependent variables (total behavior scores or subscale scores for depression, agitation, or psychosis) were influenced by site, gender, or age. Independent variables in this model included two between-group factors (site and gender) and one covariate (age). For all behavioral variables, the site and gender main effects and the site-by-gender interaction effects were not significant. Increased age was significantly related to depression subscale scores $(F=8.48, d f=1,144, p=.004, r=$ .24) and to agitation subscale scores $(F=$ $5.78, d f=1,169, p=.017, r=.19$ ). Age was not related to psychosis subscale scores. 
TABLE 7. Reported Behavioral Disturbances Versus Diagnosis

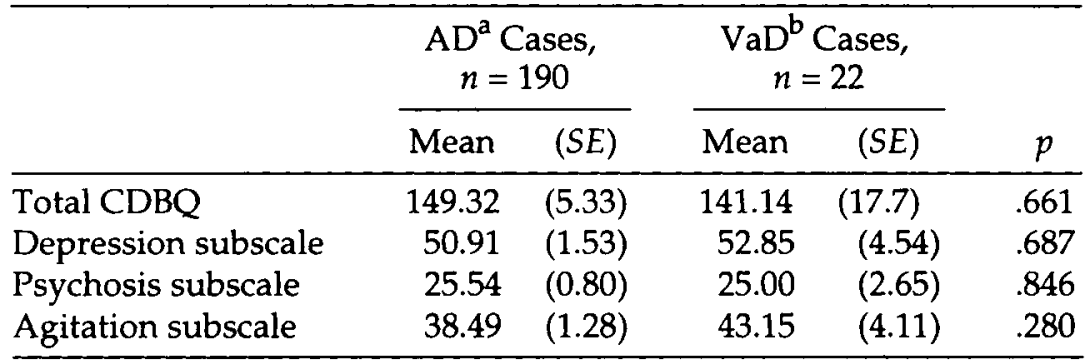

Note. $\mathrm{AD}=$ Alzheimer's disease $\mathrm{CDBQ}=$ California Dementia Behavior Questionnaire; IVD = ischemic vascular disease; $\mathrm{VaD}=$ vascular dementia.

${ }^{a}$ Probable AD plus possible AD. ${ }^{b}$ Probable IVD, possible IVD, and mixed AD/IVD.

We examined the relationship between dementia diagnosis and CDBQ scores, comparing reported behavioral disturbances in patients diagnosed with $A D$ (probable $A D$ plus possible $A D$ ) versus those thought to have a component of vascular dementia (probable IVD, possible IVD, and mixed AD/IVD). By unpaired $t$-test, there was no significant difference by diagnosis in caregiver reports of agitation, depression, or psychosis (see Table 7).

\section{Correlations Between Caregiver Ratings and Clinician Ratings of Behavior}

We examined the correlation between caregiver and clinician scores for the 66 cases examined with the battery of clinician-rated instruments. Summing the behavioral items measured by frequency (1 to 62) with those measured by severity ( 1 to 19 ) yielded a grand total score for the CDBQ. The analysis is based on less than 66 cases because a few CD$\mathrm{BQs}$ were incomplete, and the BEHAVE$A D$ was not used at the UCI site. Correlations between the CDBQ grand total and clinician-rated instruments for overall behavioral disturbance were as follows: $C D B Q$ versus $C U S P A D=0.518$ (based on 62 cases); CDBQ versus $B E-$ HAVE-AD $=0.461$ (based on 44 cases); $\mathrm{CDBQ}$ versus $\mathrm{BPRS}=0.360$ (based on 62 cases).

We also examined the correlations between subscales of the caregiver-rated CDBQ and clinician ratings on standard instruments that assessed the same aspects of behavior. These correlations are shown in Table 8.

\section{DISCUSSION}

The CDBQ was designed to facilitate a comprehensive caregiver report of behavioral disturbances in dementia. The instrument was shown to have a high internal consistency for subscales of depression, agitation, and psychosis, and thus may be a useful tool for efficiently gathering this information for research or clinical practice. We also set out to determine the reliability and validity of these measures. In the process, we came up against the inevitable challenge of this field: absent a gold standard, and given the difficulty of ascertaining psychopathology in the presence of dementia, it is intrinsically difficult to test the 
TABLE 8. Correlations Between Caregiver and Clinician Ratings of Specific Aspects of Behavior

\begin{tabular}{lc}
\hline Depression & .41 \\
CSDD vs. CDBQ Depression Subscale (62 cases) & .40 \\
Hamilton-D vs. CDBQ Depression Subscale (62 cases) & .60 \\
Agitation & .59 \\
CMAI vs. CDBQ Agitation Subscale (61 cases) & .48 \\
BEHAVE-AD items 13-18 vs. CDBQ Agitation Subscale (44 cases) & \\
Psychosis & \\
CUSPAD psychosis items vs. CDBQ Psychosis Subscale (63 cases) & \\
\hline Note. BEHAVE-AD = Behavioral Pathology in Alzheimer's Disease Rating Scale; CDBQ \\
California Dementia Behavior Questionnaire; CMAI = Cohen-Mansfield Agitation Inventory; \\
CSDD = Cornell Scale for Depression in Dementia; CUSPAD = Columbia University Scale for \\
Psychopathology in Alzheimer's Disease; Hamilton-D = Hamilton Depression Inventory.
\end{tabular}

validity of any measure of psychiatric symptoms in patients with cognitive impairment.

Based on responses to this questionnaire, individual caregivers are reliable in reporting depression, agitation, and psychotic symptoms on repeat assessments (test-retest reliability). Different caregivers of the same patient were reliable in reporting depression, fairly reliable in reporting agitation, but not reliable in reporting psychosis (interrater reliability). There are several possible explanations for the difference in interrater reliability for different behaviors: (a) untrained observers may be more likely to recognize and agree about symptoms of depression because the concept or even the personal experience of depression is more familiar than that of psychosis; (b) a depressed mood may be more likely to be observable over time, so that different caregivers may witness and report similar symptoms, whereas agitation and psychosis may be more likely to be intermittent, leading to discordant observations; (c) within the psychosis subscale there was much better interrater reliability for rating hallucinations than delusions, possibly because most caregivers would conclude that hallucinations are obviously abnormal, whereas caregivers may have different impressions of whether a given patient belief is delusional.

Comparing caregiver assessments of overall behavior disturbance with clinician assessments revealed different correlations with different standard instruments, with the highest agreement between the CDBQ and the clinicianrated CUSPAD. Even with the CUSPAD, the correlation was 0.518 , consistent with a modest agreement on overall behavior disturbance between caregivers and clinicians. It should be noted, however, that the present study is compromised by the underlying disadvantage of clinician ratings in the outpatient setting: They may often be substantially derived from information provided by the caregivers themselves. This may explain why the correlation was higher for the CUSPAD, which requires historical reports of patient behavior, and lower for the BPRS, which includes more items derived from direct clinician observation. In addition, because the clinicians interviewed caregivers and examined patients on the same clinic visit, we recognize the risk that clinician assessments may have been influenced by caregiver reports. For 
this reason, we must be cautious in contrasting clinician and caregiver ratings, particularly regarding infrequently occurring behaviors (e.g., episodes of physical aggression) for which the clinician is largely dependent on the caregiver's report.

Comparing caregiver and clinician assessments for different types of behavioral disturbance, there was a variation in the degree of agreement by type of behavior. Agitation subscale ratings exhibited the highest clinician-caregiver correlation. The psychosis subscale correlation was somewhat lower, and depression subscale ratings exhibited the lowest correlations. This finding suggests that caregivers and clinicians may be more likely to share similar impressions of patient agitation than patient psychosis or depression. In fact, it is notable that the clinician-caregiver correlation for depression rating was about half that of the caregiver interrater correlation ( 0.40 to 0.41 vs. 0.81 ). This suggests the possibility that two caregivers in the same family are more likely to share a concept of depression or to have a perception of depressive symptoms more like one another than like the clinician's perception. An alternative explanation for this discrepancy is that depression ratings on the different instruments may capture different facets of depression. The caregiver-completed $C D B Q$ is primarily derived from the frequency of symptoms, whereas the two clinician-rated instruments, the HDI and the CSDD, primarily reflect presence or absence and severity of depressive symptoms. A similar difference in the structure of items on the $C D B Q$ versus the BEHAVE-AD and CUSPAD may account for some of the disparity between caregiver and clinician ratings of agitation and psychosis. Furthermore, the comparison of caregiver and clinician ratings by type of behavior is compromised in the same way that assessments of overall behavior are: certain clinician-rated instruments (e.g., the CUSPAD and BEHAVE-AD) are more derivative from caregiver reports, whereas others (e.g., the BPRS and HDI) are more strictly based on direct observations.

The imperfect correlation between clinician and caregiver ratings of noncognitive behaviors raises two related questions: First, what factors contribute to the difference between clinician and caregiver ratings? In addition to differences in training, differences in opportunities to observe the patient, and differences in the structure of the psychometric instruments, multiple individual factors might make caregiver ratings different from clinician assessments. Psychological, cultural, and educational factors may contribute to the caregiver's perception and interpretation of patient behaviors. Caregiver depression, family dynamics, availability of emotional and financial support, and opportunities for respite may contribute to differences in caregiver tolerance of behavioral disturbances. Although several studies have reported that caregiver stress is related to patient behavioral disturbances in dementia (Hamel et al., 1990; Poulshock \& Deimling, 1984), further research is needed to determine how caregiver stress may influence caregiver perceptions of patient behaviors.

Second, what is the gold standard for ratings of behavioral disturbance in dementia? The clinician's training and experience permits expert observation. However, the clinician's assessment may be based on a period of observation of outpatients that is too brief to provide a 
full and accurate picture, whereas caregivers of outpatients are often in a better position to observe behaviors that fluctuate or occur intermittently (CohenMansfield, 1995). Specifically regarding depression, the assessment of patients with dementia is known to be difficult. Demented patients may have a reduced capacity to verbalize their subjective mood, symptoms of depression and dementia may overlap, and dementia may alter the character of depression (Cummings et al., 1995; Lazarus et al., 1987). Furthermore, hostile behaviors that are interpreted as "agitation" may actually reflect an underlying depressive disorder (Montfort, 1995). These issues make it difficult for even experts to assess depression in dementia, such that the validity of clinician ratings for depression may be lower than for more objectively observable behaviors. Further complicating this issue is the fact that, in a typical outpatient evaluation, the clinician's assessment of behavioral disturbance is often based to some degree on a caregiver interview. As a result, caregiver reports may become imbedded in clinician ratings of these behaviors, which may confound the attempt to use one rating to validate the other. Finally, we are, to some extent, at the mercy of the instruments we use: Although a specific total score may be intended to capture a discrete aspect of behavior (e.g., depression or agitation), such totals are the sum of individual items that may actually include a medley of behaviors that may or may not represent a unified construct. It might, therefore, be valuable to examine the correlations between ratings of the individual items in the behavior scales. This project is ongoing.

It is increasingly important to refine the objective assessment of noncogni- tive behaviors for diagnosis, clinical management, and research. In this regard, the finding that the match between caregiver and clinician assessments relates to the type of behavioral disturbance may be useful. Further research should clarify the factors that underlie discrepancies between caregiver and clinician assessments of behaviors in dementia.

\section{REFERENCES}

Alexopoulos, G.S., Abrams, R.C., Young, R.C., \&Shamoian, C. A. (1988). Cornell scale for depression in dementia. Biological Psychiatry, 23, 271-284.

Asada, T., Yoshioka, M., Morikawa, S., Koyama, H., Kitajima, E., et al. (1994). Development of a troublesome behavior scale (TBS) for elderly patients with dementia. Nippon Koshu Eisei Zasshi IJapanese Journal of Public Health], 41, 518-527.

Burns, A., Jacoby, R., \& Levy, R. (1990). Psychiatric phenomena in Alzheimer's disease: 1 . Disorders of thought content. British Journal of Psychiatry, 157, 72-76.

Chenoweth, B., \& Spencer, B. (1986). Dementia: The experience of family caregivers. The Gerontologist , 26, 267-272.

Chui, H., Victoroff, J. I., Margolin, D., Jagust, W., Shankle, R., \& Katzman, R. (1992). Criteria for the diagnosis of ischemic vascular dementia proposed by the State of California Alzheimer Disease Diagnostic and Treatment Centers (ADDTC). Neurology, 42, 473-480.

Cohen, C. A., Gold, D. P., Shulman, K. I., Wortley, J. T., McDonald, G., et al. (1993). Factors determining the decision to institutionalize dementing individuals: A prospective study. The Gerontologist, 33, 714-720.

Cohen-Mansfield, J. (1995). Assessment of disruptive behavior/agitation in the elderly: Function, methods, and difficulties. Journal of Geriatric Psychiatry and Neurology, 8, 52-60. 
Cohen-Mansfield, J., Marx, M. S., \& Rosenthal, A. S. (1989). A description of agitation in a nursing home. Journal of Gerontology, Medical Sciences, 44(Suppl.), M77-M84.

Cummings, J. L., Ross, W., Absher, J., Gornbein, J., \& Hadjiaghai, L. (1995). Depressive symptoms in Alzheimer's disease: Assessment and determinants. Alzheimer Disease and Associated Disorders, 9, 87-93.

Cummings, J. L., \& Victoroff, J. I. (1990). Noncognitive neuropsychiatric syndromes in Alzheimer's disease. Neuropsychiatry, Neuropsychology, and Behavioral Neurology. 3, 40-158.

de Jonge, J. F., Kat, M. G., Rottier, W. P., \& de Reus, R. (1995). The Behavior Observation Scale for intramural psychogeriatrics and clinical diagnosis: A comparison with the BOP (Assessment Elderly Patients) and NOSIE-30. Tijdschrift Voor Gerontologie en Geriatrie, 26, 24-29.

Devanand, D. P., Miller, L., Richards, M., Marder, K., Bell, K., et al. (1992). The Columbia University scale for psychopathology in Alzheimer's disease. Archives of Neurology, 49, 371-376.

Gilley, D. W., Whalen, M. E., Wilson, R. S., \& Bennett, D. A. (1991). Hallucinations and associated factors in Alzheimer's disease. Journal of Neuropsychiatry and Clinical Neuroscience, 3, 371-376.

Hamel, M., Gold, D. P., Andres, D., Reis, M., Dastoor, D., et al. (1990). Predictors and consequences of aggressive behavior by community-based dementia patients. The Gerontologist, 30, 206-21l.

Hamilton, M. (1960). A rating scale for depression. Journal of Neurology, Neurosurgery, and Psychiatry, 23, 56-62.

Kumar, A., Koss, E., Metzler, D., Moore, A., \& Friedland, R. P. (1988). Behavioral symptomatology in dementia of the Alzheimer type. Alzheimer Disease and Associated Disorders, 2, 363-365.

Lazarus, L. W., Newton, N., Cohler, B., Lesser, J., \& Schweon, C. (1987). Frequency and presentation of depressive symptoms in patients with primary degenerative de- mentia. American Journal of Psychiatry, 144, 41-45.

Lukovits, T. G., \& McDaniel, K. D. (1992). Behavioral disturbance in severe Alzheimer's disease: A comparison of family member and nursing staff reporting. Journal of the American Geriatrics Society, 40, 891-895.

McKhann, G., Drachman, D., Folstein, M., Katzman, R., Price, D., etal. (1984). Clinical diagnosis of Alzheimer's disease: Report of the NINCDS-ADRDA Work Group under the auspices of Department of Health and Human Services Task Force on Alzheimer's Disease. Neurology, 34, 939944.

Merriam, A. E., Aronson, M. K., Gaston, P., Wey, S. L., \& Katz, I. (1988). The psychiatric symptoms of Alzheimer's disease. Journal of the American Geriatrics Society, 36, 7-12.

Monfort, J. C. (1995). The difficult elderly patient: Curable hostile depression or personality disorder? International Psychogeriatrics, 7(Suppl.), 95-111.

Overall, J. E., \& Gorham, D. R. (1962). The brief psychiatric rating scale. Psychological Reports, 10, 799-812.

Patterson, M. B., \& Bolger, J. P. (1994). Assessment of behavioral symptoms in Alzheimer disease. Alzheimer Disease and Associated Disorders, 8(Suppl. 3), 4-20.

Poulshock, S. W., \& Deimling, G. T. (1984). Families caring for elders in residence: Issues in the measurement of burden. Journal of Gerontology, 39, 230-239.

Reisberg, B., Borenstein, J., Salob, S. P., Ferris, S. H., Franssen, E., et al. (1987). Behavioral symptoms in Alzheimer's disease: Phenomenology and treatment. Journal of Clinical Psychiatry, 48(Suppl.), 9-15.

Sattel, H., Geiger-Kabisch, C., Schreiter-Gasser, U., Besthorn, C., \& Forstl, H. (1993). Incidence and importance of "non-cognitive" symptoms in dementia of the Alzheimer type: Productive psychotic symptoms, depressive disorders and behavioral disorders. Zeitschrift fur Gerontologie, 26, 275-279. 
Seltzer, B., \& Buswell, A. (1994). Psychiatric symptoms in Alzheimer's disease: Mental status examination versus caregiver report. The Gerontologist, 34, 103-109.

Swearer, J. M., Drachman, D. A., O'Donnell, B. F., \& Mitchell, A. L. (1988). Troublesome and disruptive behaviors in dementia. Journal of the American Geriatrics Society, 36, 784-790.

Teri, L., Larson, E. B., \& Reifler, B. V. (1988). Behavioral disturbance in dementia of the Alzheimer's type. Journal of the American Geriatrics Society, 36, 1-6.

Teri, L., \& Wagner, A. W. (1991). Assessment of depression in patients with Alzheimer's disease: Concordance among informants. Psychology and Aging, 6, 280-285.

Weiner, M. F., Koss, E., Wild, K. V., Folks, D. G., Tariot, P., et al. (1996). Measures of psychiatric symptoms in Alzheimer patients: A review. Alzheimer Disease and Associated Disorders, 10, 20-30.
Zarit, S. H., Reever, K. E., \& Bach-Peersen, J. (1980). Relatives of the impaired elderly: Correlates of feelings of burden. The Gerontologist, 20, 649-655.

Zung, W. W. K. (1965). A self-rating depression scale. Archives of General Psychiatry, 12, 6370.

Acknowledgments. A preliminary report of these results was presented at the 12 th Annual Research Consortium of the California Alzheimer's Disease Diagnostic and Treatment Centers, Lake Arrowhead, California, April 24, 1996. This project was supported by National Institute on Aging grant IPSO AG10129 and by the State of California Department of Health Services Alzheimer's Disease Program contract nos. 91-13051 and 91-13046.

(Appendix starts on next page) 


\section{APPENDIX \\ California Dementia Behavior Questionnaire}

Patient name

Date

Caregiver name (person filling out this form)

Relationship to the patient

Do you spend most of every day with the patient? yes/no

This questionnaire lists behavior problems or kinds of behavior change.

Please place a check mark in the "Present in the last 6 months" column to indicate any behavior that has been present in the last six months, even if you don't consider it a problem. Then, for each behavior indicate how often it has been present during the last month. Indicate how often it occurred in the last month as follows:

Never $=\quad$ Has not occurred in the last month.

Rarely $=\quad$ Has occurred once or twice in the last month.

Weekly $=$ Has occurred once a week or every few days.

Daily $=\quad$ Has occurred almost every day or daily.

Constantly = Has occurred many times each day.

\begin{tabular}{|l|l|l|l|l|l|l|l|}
\hline & \multicolumn{2}{|c|}{$\begin{array}{c}\text { Was this } \\
\text { symptom } \\
\text { present } \\
\text { in last 6 } \\
\text { months? }\end{array}$} & If yes, how often present in the last month? \\
\hline Observation & Yes & No & Never & Rarely & Weekly & Daily & Constantly \\
\hline $\begin{array}{l}\text { 1. Is forgetful or has poor } \\
\text { memory. }\end{array}$ & & & & & & & \\
\hline $\begin{array}{l}\text { 2. Becomes confused or } \\
\text { disoriented. }\end{array}$ & & & & & & & \\
\hline 3. Is easily distracted. & & & & & & & \\
\hline $\begin{array}{l}\text { 4. Has problems } \\
\text { expressing self verbally. }\end{array}$ & & & & & & & \\
\hline 5. Gets lost easily. & & & & & & & \\
\hline $\begin{array}{l}\text { 6. Talks about feeling sad } \\
\text { or depressed. }\end{array}$ & & & & & & & \\
\hline 7. Is tearful. & & & & & & & \\
\hline $\begin{array}{l}\text { 8. Talks about being a } \\
\text { failure, inadequate, or } \\
\text { worthless. }\end{array}$ & & & & & & & \\
\hline
\end{tabular}




\begin{tabular}{|l|l|l|l|l|l|l|l|}
\hline & \multicolumn{2}{|c|}{$\begin{array}{c}\text { Was this } \\
\text { symptom } \\
\text { present } \\
\text { in last 6 } \\
\text { months? }\end{array}$} & If yes, how often present in the last month? \\
Observation & Yes & No & Never & Rarely & Weekly & Daily & Constantly \\
\hline $\begin{array}{l}\text { 9. Talks about things s/he } \\
\text { has done wrong. }\end{array}$ & & & & & & & \\
\hline $\begin{array}{l}\text { 10. Complains of problems } \\
\text { with thinking or } \\
\text { concentration. }\end{array}$ & & & & & & & \\
\hline $\begin{array}{l}\text { 11. Says life is not worth } \\
\text { living. }\end{array}$ & & & & & & & \\
\hline 12. Talks about suicide. & & & & & & & \\
\hline $\begin{array}{l}\text { 13. Worries too much about } \\
\text { things. }\end{array}$ & & & & & & & \\
\hline $\begin{array}{l}\text { 14. Has episodes of } \\
\text { extreme anxiety or panic. }\end{array}$ & & & & & & & \\
\hline $\begin{array}{l}\text { 15. Has irrational fear(s) of } \\
\text { objects or situations. }\end{array}$ & & & & & & & \\
\hline $\begin{array}{l}\text { 16. Makes inappropriate } \\
\text { sexual comments. }\end{array}$ & & & & & & & \\
\hline $\begin{array}{l}\text { 17. Engages in inappropriate } \\
\text { sexual behavior. }\end{array}$ & & & & & & & \\
\hline $\begin{array}{l}\text { 18. Displays other } \\
\text { embarrassing or } \\
\text { inappropriate } \\
\text { behavior. }\end{array}$ & & & & & & & \\
\hline 19. Wanders. & & & & & & & \\
\hline 20. Paces back and forth. & & & & & & & \\
\hline $\begin{array}{l}\text { 21. Follows caregiver } \\
\text { wherever s/he goes. }\end{array}$ & & & & & & & \\
\hline 22. Hides or hoards things. & & & & & & & \\
\hline $\begin{array}{l}\text { 23. Engages in purposeless } \\
\text { activity. }\end{array}$ & & & & & & & \\
\hline $\begin{array}{l}\text { 24. Repeats same behavior } \\
\text { over and over. }\end{array}$ & & & & & & & \\
\hline
\end{tabular}




\begin{tabular}{|c|c|c|c|c|c|c|c|}
\hline \multirow[t]{2}{*}{ Observation } & \multicolumn{2}{|c|}{$\begin{array}{l}\text { Was this } \\
\text { symptom } \\
\text { present } \\
\text { in last } 6 \\
\text { months? }\end{array}$} & \multicolumn{5}{|c|}{ If yes, how often present in the last month? } \\
\hline & Yes & No & Never & Rarely & Weekly & Daily & Constantly \\
\hline $\begin{array}{l}\text { 25. Repeats questions or } \\
\text { stories. }\end{array}$ & & & & & & & \\
\hline 26. Is fidgety, can't sit still. & & & & & & & \\
\hline $\begin{array}{l}\text { 27. Complains of trouble } \\
\text { sleeping. }\end{array}$ & & & & & & & \\
\hline $\begin{array}{l}\text { 28. Has difficulty sleeping at } \\
\text { night. }\end{array}$ & & & & & & & \\
\hline $\begin{array}{l}\text { 29. Complains of sleeping } \\
\text { too much. }\end{array}$ & & & & & & & \\
\hline 30. Sleeps too much. & & & & & & & \\
\hline 31. Has increased appetite. & & & & & & & \\
\hline 32. Has poor appetite. & & & & & & & \\
\hline 33. Has gained weight. & & & & & & & \\
\hline 34. Has lost weight. & & & & & & & \\
\hline $\begin{array}{l}\text { 35. Is physically violent with } \\
\text { other people. }\end{array}$ & & & & & & & \\
\hline $\begin{array}{l}\text { 36. Hits, kicks, or throws } \\
\text { objects in anger. }\end{array}$ & & & & & & & \\
\hline $\begin{array}{l}\text { 37. Has verbal outbursts of } \\
\text { anger. }\end{array}$ & & & & & & & \\
\hline $\begin{array}{l}\text { 38. Uncooperative with } \\
\text { caregiver. }\end{array}$ & & & & & & & \\
\hline 39. Is irrationally jealous. & & & & & & & \\
\hline 40. Is very suspicious. & & & & & & & \\
\hline $\begin{array}{l}\text { 41. Believes others are } \\
\text { plotting against or want } \\
\text { to hurt her } / \mathrm{him} \text {. }\end{array}$ & & & & & & & \\
\hline
\end{tabular}




\begin{tabular}{|c|c|c|c|c|c|c|c|}
\hline \multirow[t]{2}{*}{ Observation } & \multicolumn{2}{|c|}{$\begin{array}{l}\text { Was this } \\
\text { symptom } \\
\text { present } \\
\text { in last } 6 \\
\text { months? }\end{array}$} & \multicolumn{5}{|c|}{ If yes, how often present in the last month? } \\
\hline & Yes & No & Never & Rarely & Weekly & Daily & Constantly \\
\hline $\begin{array}{l}\text { 42. Has unreal belief that } \\
\mathrm{s} / \text { he has a serious illness } \\
\text { or physical problem. }\end{array}$ & & & & & & & \\
\hline $\begin{array}{l}\text { 43. Has unreal belief that } \\
\text { her/his body is not } \\
\text { working properly. }\end{array}$ & & & & & & & \\
\hline $\begin{array}{l}\text { 44. Has unreal belief that } \\
\text { s/he has exceptional } \\
\text { powers, talents or } \\
\text { abilities. }\end{array}$ & & & & & & & \\
\hline $\begin{array}{l}\text { 45. Believes that people are } \\
\text { stealing things from } \\
\text { her/him. }\end{array}$ & & & & & & & \\
\hline $\begin{array}{l}\text { 46. Believes spouse or } \\
\text { significant other has } \\
\text { been unfaithful. }\end{array}$ & & & & & & & \\
\hline $\begin{array}{l}\text { 47. Believes sh/he will be } \\
\text { abandoned. }\end{array}$ & & & & & & & \\
\hline $\begin{array}{l}\text { 48. Believes that spouse or } \\
\text { caregiver is an imposter. }\end{array}$ & & & & & & & \\
\hline $\begin{array}{l}\text { 49. Believes that place } s / \text { he } \\
\text { is living is not her/his } \\
\text { home. }\end{array}$ & & & & & & & \\
\hline $\begin{array}{l}\text { 50. Believes TV shows are } \\
\text { real. }\end{array}$ & & & & & & & \\
\hline $\begin{array}{l}\text { 51. Does not recognize own } \\
\text { image in mirror. }\end{array}$ & & & & & & & \\
\hline
\end{tabular}




\begin{tabular}{|c|c|c|c|c|c|c|c|}
\hline \multirow[t]{2}{*}{ Observation } & \multicolumn{2}{|c|}{$\begin{array}{l}\text { Was this } \\
\text { symptom } \\
\text { present } \\
\text { in last } 6 \\
\text { months? }\end{array}$} & \multicolumn{5}{|c|}{ If yes, how often present in the last month? } \\
\hline & Yes & No & Never & Rarely & Weekly & Daily & Constantly \\
\hline $\begin{array}{l}\text { 52. Does not recognize or } \\
\text { misidentifies familiar } \\
\text { people. }\end{array}$ & & & & & & & \\
\hline $\begin{array}{l}\text { 53. Sees people or objects } \\
\text { that aren't there. }\end{array}$ & & & & & & & \\
\hline $\begin{array}{l}\text { 54. Sees lights or colors that } \\
\text { aren't there. }\end{array}$ & & & & & & & \\
\hline $\begin{array}{l}\text { 55. Hears words or voices } \\
\text { that aren't there. }\end{array}$ & & & & & & & \\
\hline $\begin{array}{l}\text { 56. Hears sounds that aren't } \\
\text { there. }\end{array}$ & & & & & & & \\
\hline $\begin{array}{l}\text { 57. Feels sensations (like } \\
\text { being touched) when } \\
\text { there's nothing there. }\end{array}$ & & & & & & & \\
\hline $\begin{array}{l}\text { 58. Smells odors that aren't } \\
\text { there. }\end{array}$ & & & & & & & \\
\hline $\begin{array}{l}\text { 59. Tastes things that aren't } \\
\text { there. }\end{array}$ & & & & & & & \\
\hline $\begin{array}{l}\text { 60. Hears a sound but thinks } \\
\text { it is something else (e.g., } \\
\text { thinks a phone ring is a } \\
\text { siren). }\end{array}$ & & & & & & & \\
\hline $\begin{array}{l}\text { 61. Sees something but } \\
\text { thinks it is something } \\
\text { else (e.g., thinks a pillow } \\
\text { is a person). }\end{array}$ & & & & & & & \\
\hline $\begin{array}{l}\text { 62. Feels a sensation but } \\
\text { thinks it is something } \\
\text { else (e.g., something } \\
\text { touching her } / \text { him). }\end{array}$ & & & & & & & \\
\hline
\end{tabular}


Changes in mood and emotion are listed below. Please indicate the degree of each item, or how much you have been aware of it, DURING THE LAST MONTH. Use the following guidelines for ratings:

1. Not present $=$ The behavior has not been observed.

2. Mild = The behavior can be seen by someone who is looking for it, it is abnormal, but it is not very intense. If you do something to help, or change the situation, the behavior will often improve.

3. Moderate $=$ The behavior is easily noticed. Intensity is moderate. The behavior is often seen throughout the day. Changes in the situation or strong efforts by others to help may improve the behavior a little.

4. Severe $=$ The behavior is unmistakable. Intensity is high. The behavior may be almost the only thing you notice about the person. Almost nothing helps.

\begin{tabular}{|c|c|c|c|c|}
\hline Observation during the last month & $\begin{array}{c}\text { Not } \\
\text { Present }\end{array}$ & Mild & Moderate & Severe \\
\hline 1. Appears sad or depressed. & & & & \\
\hline 2. Does not seem to enjoy anything. & & & & \\
\hline 3. Has low energy, becomes tired eas & & & & \\
\hline 4. Is nervous, anxious, or tense. & & & & \\
\hline 5. Reacts angrily to minor frustration & & & & \\
\hline 6. Demands must be met immediate & & & & \\
\hline 7. Is excitable or impulsive. & & & & \\
\hline 8. Is agitated or distressed. & & & & \\
\hline $\begin{array}{l}\text { 9. Mood or emotions change quickly } \\
\text { dramatically. }\end{array}$ & & & & \\
\hline 10. Has little or no interest in things. & & & & \\
\hline 11. Does not seem to care about anyth & & & & \\
\hline $\begin{array}{l}\text { 12. Not interested in interacting with } \\
\text { others. }\end{array}$ & & & & \\
\hline 13. Shows little emotional response. & & & & \\
\hline 14. Has little sense of humor. & & & & \\
\hline 15. Is restless or overactive. & & & & \\
\hline 16. Speaks or moves slowly. & & & & \\
\hline $\begin{array}{l}\text { 17. Shows excessive or inappropriate } \\
\text { humor. }\end{array}$ & & & & \\
\hline 18. Has craving for sweet foods. & & & & \\
\hline 19. Thinks slowly. & & & & \\
\hline
\end{tabular}




\section{Caregiver Experience Questions}

The following questions refer to how you, the caregiver, feel. Please answer these questions about how things have gone for you in the last month:

\begin{tabular}{|l|l|l|l|l|}
\hline & Never & Rarely & $\begin{array}{c}\text { Quite } \\
\text { frequently }\end{array}$ & $\begin{array}{c}\text { Nearly } \\
\text { always }\end{array}$ \\
\hline $\begin{array}{l}\text { 1. Do you feel stressed between caring for your } \\
\text { relative and trying to meet other } \\
\text { responsibilities for your family or work? }\end{array}$ & & & & \\
\hline $\begin{array}{l}\text { 2. Are you afraid what the future holds for } \\
\text { your relative? }\end{array}$ & & & & \\
\hline 3. Do you feel down-hearted, blue, and sad? & & & & \\
\hline 4. Do you have crying spells or feel like it? & & & & \\
\hline 5. Do you get tired for no reason? & & & & \\
\hline $\begin{array}{l}\text { 6. Overall, how burdened do you feel in caring } \\
\text { for your relative? }\end{array}$ & & & & \\
\hline
\end{tabular}

\section{Comments:}

